\title{
Do lado de lá: um estudo etnográfico sobre as homossociabilidades que se constituem nas periferias da cidade de São Paulo
}

\author{
Maíra Kobayashi*
}

\begin{abstract}
Resumo: Este artigo é resultado de uma pesquisa ainda em andamento sobre as sociabilidades homossexuais que se constituem nas periferias da cidade de São Paulo. A partir de pesquisa etnográfica em três casas noturnas localizadas na zona leste de São Paulo, o artigo tem como objetivo compreender as dinâmicas sociais de gays e lésbicas, procurando através dessas relações identificar as subjetividades dos diferentes sujeitos, relacionando-os com marcadores sociais de diferença, como a classe social, raça, gênero, geração, sexualidade e corporalidade. Ao tentar manter relações tanto com a sociologia como com a antropologia, o presente artigo aparece mais como um experimento, na tentativa de buscar um maior aprofundamento para se pensar a construção das identidades marginais através do urbano, da territorialidade e da orientação sexual.
\end{abstract}

Palavras-chave: sexualidade, gênero, identidade, periferias.

Falar de periferia é ainda um tema um pouco delicado nas Ciências Sociais, complexidade que se agrava quando relacionamos as (homo)sexualidades que se constituem nas periferias de uma metrópole como São Paulo. Devido a essas dificuldades e por ainda ser um campo relativamente novo a ser explorado, esse artigo aparece mais como um experimento na tentativa de mesclar autores da sociologia e da antropologia para se pensar a construção das identidades desviantes. A reflexão do homem marginal de Florestan Fernandes me parece primordial para se pensar o quanto a situação do marginal é privilegiada para uma reflexão mais audaz, ou seja, ao olharmos da perspectiva do dominado ou do estigmatizado conseguimos ter um maior campo crítico para análises mais contundentes.

Sendo assim, o presente artigo procura analisar os processos de homossociabilidades presentes nas periferias da cidade de São Paulo. Ao revelar diferentes olhares e dar voz a diferentes sujeitos pretende-se identificar as percepções e subjetividades desses atores, tanto em relação ao centro da cidade como em relação a sua identidade enquanto homossexual. Com isso, sua relevância consiste em dar voz

* Graduanda em Ciências Sociais - PUC-SP. 
àqueles que não têm chance de mostrar sua própria interpretação frente a uma cidade em constante movimento. Procuro analisar como o homossexual das diferentes periferias da cidade de São Paulo vive, interpreta e representa sua própria cidade e sua identidade.

Portanto, o artigo encaminha-se para a necessidade de se pensar as especificidades dos diferentes sujeitos das diferentes periferias. As três casas visitadas na zona leste de alguma forma ajudam a construir o sujeito homossexual de periferia, demarcando entre gerações, relações performativas de gênero, estratos sociais, sexualidade, entre outros marcadores sociais de diferença. Uma delas, em Itaquera, é composta por um público bem jovem de "moderninhos"1, esteticamente falando, que gostam do cenário alternativo. Já em São Mateus, há uma boate em que seus frequentadores - travestis, gays e lésbicas - curtem "bate-cabelo"2. Outra casa também em São Mateus se define mais como uma boate com videokê, onde há uma grande presença de homossexuais na faixa dos 30 anos que gostam de cantar músicas nacionais, como MPB e sertanejo. Sendo assim, pretende-se trazer nesse paper um breve relato dessas três casas noturnas, mostrando as especificidades de cada uma delas e o quanto colaboram para a construção de diferentes sujeitos e para a demarcação de fronteiras.

\section{Os "quase moderninhos"3 da Plasticine}

Em uma rua tranquila a quinze minutos do metrô Itaquera, encontra-se uma casa noturna chamada Luar Rock Bar. Há onze anos essa casa promove shows para bandas de rock do cenário independente. Há três anos e meio, impulsionada pela queda do público nessa casa, iniciou-se uma festa intitulada "Plasticine", nome que remete a uma música da banda de rock inglesa Placebo. De acordo com o organizador dessa festa, ela começou tocando músicas do cenário indie rock e, com o passar do tempo, houve a inclusão do pop. A mudança de público vai ocorrendo gradati-

\footnotetext{
${ }^{1}$ Esse termo vem sendo bastante utilizado na mídia, e define basicamente um tipo de público com um determinado estilo restrito que escapa ao visual comum.

${ }^{2}$ Estilo de dança e música tradicional na cena GLS, em que a artista gira abruptamente a cabeça de forma a deixar a peruca/cabelo rodopiando freneticamente.

${ }^{3}$ Esse termo foi extraído do tópico "Quase bonitos, quase modernos", da dissertação de Isadora Lins França. 0 termo "quase", de acordo com a autora, anuncia limites mediante distinções, sendo que "um deslize pode ser considerado como indício de não-pertencimento" (FRANÇA, 2006, p. 79).
} 
vamente, fazendo com que hoje seus frequentadores peçam em todas as festas a inclusão do funk.

As observações feitas em campo levam a acreditar que a casa se encontra em transição. Em conversas informais com frequentadores dessa casa, observou-se as disputas simbólicas que envolvem esse lugar. Com uma estrutura que remete aos famosos circuitos de rock de São Paulo, juntamente com a própria história da casa que servia como ponto de encontro para o público do rock do cenário independente, há ainda por parte dos veteranos um enorme incômodo com a mudança de público dessa casa. Houve depoimentos onde homens heterossexuais disseram sentir-se incomodados com a forte presença de "viadinhos" na casa. Esse rapaz, especificamente, além de não estar gostando da presença de gays na festa, revelou que irá parar de frequentar também pelo fato de seus amigos terem parado de ir. Outro homem heterossexual disse que só frequentava a festa para "comer", devido à facilidade de conseguir uma relação sexual tanto pela faixa etária das meninas, como pelo fato de estarem sempre embriagadas. Também reclamou da grande presença de lésbicas que não davam entrada para homens.

Fato curioso na Plasticine foi a discrepância dos depoimentos com seus mais diversos frequentadores. Para a maior parte do público que se autointitula heterossexual abordado, a presença de homossexuais é minoritária, não dando assim para ser considerada como uma festa GLS. Já para grande parte do público homossexual, a festa, apesar de ter características alternativas, pode ser considerada como GLS, já que para estes há a presença de oitenta a noventa por cento de homossexuais que ocupam este lugar. Apesar de não ser uma casa propriamente GLS, essa festa serve como ponto de encontro semanal para adolescentes e jovens homossexuais trocarem experiências.

Esse conflito da própria identidade da festa, assim como a dificuldade para o entendimento daquele público e daquele espaço, motivaram a procura por conexões com o circuito Centro-Augusta-Barra Funda, de forma que fosse possível analisar os pontos de aproximação e distanciamento entre o pedaço e o circuito ${ }^{4}$. Parece que na Plasticine há uma tentativa de aproximação estética - visto na vestimenta, acessórios, corte ou cor de cabelo - com o público alternativo presente em grande parte no

\footnotetext{
${ }^{4}$ Os termos pedaço e circuito são usados aqui segundo o sentido proposto por Magnani (1996).
} 
circuito alternativo de São Paulo. Porém, as músicas tocadas nessa festa não fazem dela alternativa se entendermos que o cenário alternativo diz respeito a um comportamento, caráter estético e estilos musicais que não são comercializados ${ }^{5}$. Sendo assim, ao tocar funks famosos como MC Beyoncé ou pop internacional como Britney Spears e Lady Gaga, ela já não se encaixa na cena alternativa ou independente.

O que se pode concluir a partir daí é que a tentativa de aproximação do visual 'moderninho' presente no circuito alternativo de São Paulo - que faz com que grande parte desse público frequente ou tenha forte interesse em conhecer esse circuito, indo para boates localizadas em regiões mais centrais em São Paulo - acaba por legitimar o padrão 'moderninho' de conduta. Porém esse padrão 'moderninho' tem rachaduras na medida em que segue apenas um gosto estético de vestimenta, deixando de lado a essência do ser alternativo. Como diz Bourdieu (1983) ao analisar a relação intrínseca entre os gostos de classe e o estilo de vida, há uma tentativa das camadas menos favorecidas em seguir o gosto estético dominante, porém essa tentativa é sempre falha na medida em que não se leva em consideração o constante movimento de distanciamento das camadas favorecidas em relação às camadas populares, buscando assim um grau maior de diferenciação.

Outro ponto observado é que esse público tem como referência a centralidade, ou seja, apesar de morarem em bairros do extremo leste da cidade ${ }^{6}$, usam o termo zona leste para designar pessoas, homossexuais ou não, de forma pejorativa. Um dos entrevistados ao ser indagado sobre o que era uma "bicha estranha", termo que ele utilizou recorrentemente na entrevista, me explicou:

Bichinha feia, pobre, sabe, aquelas bem.... sei lá... David Brazil. Éhh, não sei como dizer. É aquelas bichas que tipo, ai sei lá, é da zona leste, nem sei se mora na zona leste, mas tem cara de zona leste. Tipo aquelas que tem piercing aqui na sombrancelha, ou um piercing aqui, que usa aqueles boné da barraca, que usa aquelas camisa colada da $\mathrm{C} \& \mathrm{~A}$, nada contra a C\&A porque eu compro roupa lá também, mas a parte mais feia da C\&A. Aquelas calça manchada, aqueles Nike véio, Mizuno, Rebook. Ai é muito sei lá, é umas bicha estranha. $^{7}$

\footnotetext{
${ }^{5}$ Como aponta Facchini (2008), as meninas do cenário alternativo na cidade de São Paulo têm como referência as músicas europeias, além das roupas de grife descoladas, de forma a dar um ar desleixado. Soma-se também a isso o interesse por determinadas produções culturais artísticas restritas, tanto no âmbito nacional como internacional.

${ }^{6}$ Grande parte dos frequentadores dessa festa moram em regiões como Itaquera, Itaim Paulista, Guaianazes, São Miguel Paulista e Cidade Tiradentes.

${ }^{7}$ Entrevista realizada em agosto de 2012, durante pesquisa de campo.
} 
Parece que, como grande parte do público da Plasticine frequenta o circuito homossexual e/ou alternativo, eles adjetivam o termo zona leste por sofrer discriminação em outros ambientes localizados em regiões mais centrais. Assim como por parte dos moradores das periferias leste há uma busca pela diferenciação entre o criminoso e o trabalhador, como aponta Clemente (1998), há também por parte dos homossexuais a busca por diferenciação expressada em constantes comparações entre a "bichinha" e o "gay" ou "homossexual". Um dos entrevistados, um jovem de 23 anos, me disse que não gosta de morar em seu bairro porque além de ser longe de tudo, ele sente muita discriminação quando fala que mora em Guaianazes.

Outra entrevistada também disse que a zona leste tem uma cara, porém diferentemente do primeiro entrevistado, a cara da zona leste é a violência.

\begin{abstract}
Posso ser sincera? No Jardins o pessoal é a cara da riqueza, aqui na zona leste é a cara da pobreza. Então eu queria morar no Jardins, acho que eu ia me sentir mais confortável do que aqui. Porque aqui só sai tiroteio, o pessoal anda armado, só tem droga, entendeu? No Jardins é um clima diferente, é um ambiente diferente, são pessoas que sabem ser cidadãos. $^{8}$
\end{abstract}

O interessante nessa fala é que ela não diz que Itaquera é a 'cara da pobreza', mas sim a zona leste como um todo. Como quase quatro milhões de habitantes podem ter uma cara? Os dois dizem que a zona leste tem uma cara, em um caso a 'cara da zona leste' remete a atribuição de um significado através de acessórios corporais como o piercing, boné, camisa, calça e tênis. No outro caso, a 'cara da zona leste' se refere à classe social, à violência e ao tráfico de drogas - ou ao uso de drogas.

Apesar de ambos nunca terem presenciado violência ou criminalidade próximo ao seu local de moradia, acabam por reproduzir um discurso que visa homogeneizar a zona leste como o local do perigo, da desordem, do esteticamente feio e do mau gosto.

\title{
A irreverência no Guinga's Bar
}

O Guinga's Bar é uma casa localizada próximo ao terminal São Mateus. A casa é dividida em três ambientes: a pista de dança com bar que chega a ficar cheia aos sábados; um espaço com pouca iluminação com mesas e cadeiras, e um outro am-

\footnotetext{
${ }^{8}$ Entrevista realizada em outubro de 2012, durante pesquisa de campo.
} 
biente com videokê, bar e mesas. A faixa etária média do público é de 30 anos, e seus frequentadores se dividem proporcionalmente entre gays e lésbicas. Já em relação a marcadores raciais, a casa também é bem dividida entre brancos e pardos. Todos os entrevistados e pessoas com quem conversei tinham como nível de instrução o Ensino Médio completo, muitos também, principalmente entre o público na faixa dos 24 anos, estavam cursando a graduação. Alguns tinham o Ensino Superior completo.

Acredito que a categoria "pedaço" proposta por Magnani pode ser importante para análise da descrição de uma forma específica de sociabilidade. De acordo com o autor, os frequentadores do pedaço "se reconheciam como portadores dos mesmos símbolos que remetem a gostos, orientações, valores, hábitos de consumo e modos de vida semelhantes" (MAGNANI, 2002, p. 22). Sendo assim, foi identificada nessa casa uma certa homogeneidade de comportamento e pensamento de seus frequentadores. A recusa com pessoas e baladas das regiões centrais, como também constantes comparações entre as diversas casas noturnas e regiões da cidade, parecem algo corriqueiro. Para melhor explicitar o que se pretende dizer aqui, segue a transcrição da fala de duas entrevistadas:

\begin{abstract}
As pessoas [daqui] gostam de uma amizade, gostam de conversar, por mais que no decorrer do tempo você vai conhecendo realmente quem é aquela pessoa, não é aquela que você pensava que era. As pessoas são mais humilde, as pessoas são mais aberta, as pessoas são mais... tem espaço, tem mais atitude, acho mó barato aqui na zona leste!... que eu já tive convivência, tipo assim com as minhas ex e tal que... só teve a última que foi da zona leste, mas a outra foi da zona oeste e a outra foi da zona sul. E tipo assim completamente diferente, é mó... é completamente estranho! Tipo a cabeça em si da pessoa não bate, uma pessoa mais arrogante, uma pessoa mais fria pela convivência por onde morar, é completamente diferente $!^{9}$
\end{abstract}

A reação de estranhamento com as pessoas das zonas sul e oeste, juntamente com a positivação da zona leste, aparece também na fala de outra entrevistada, porém a diferença da outra entrevistada é que ela não divide essa diferença em zonas, mas sim em classes sociais. Moradora de Mauá, ela frequentava diversas casas GLS na região oeste, sul e central de São Paulo, porém disse que parou de andar nessas casas devido à "podridão" desse público. No trecho que segue abaixo, ela fala sobre um suposto mascaramento de sua identidade, fazendo com que se recolhesse à sua

\footnotetext{
${ }^{9}$ Entrevista realizada em setembro de 2012, durante pesquisa de campo.
} 
região de moradia, local onde podia ser ela mesma e se sentir bem. Em outros momentos da entrevista, ela também cita a forte presença do alcoolismo e de substâncias ilícitas nessas casas, além da arrogância de seus frequentadores:

Se você for, aonde eu vou te dizer agora, na $B u b u$, não sei se vocês chegaram a ir lá, vai lá pra você ver se tem o mesmo calor humano que aqui. Não tem. As pessoas são classe média alta, então já te olha com segundos olhos (...) Eu ia pra Bubu, Tunnel, Madame Satã, Clube Z, que é no Itaim também, fechou, Clube A que também é meio dividido, entendeu? Essas classes assim. Então eu parei, eu sou muito de observar as coisas e as pessoas. Então eu falei: meu, o que eu tô fazendo aqui? Tô sendo uma pessoa que eu não sou, você tá entendendo? (...) Então eu falei: não, não é mais a minha cultura, não é mais o meu fluxo, eu vou partir para o meu lado, do município que é do meu lado A, B, C, D, é aonde eu vivo e me dou muito bem. ${ }^{10}$

Temos assim, em um caso, o estranhamento com pessoas das regiões oeste e sul, e no outro, o distanciamento com as classes média/média alta. No primeiro caso, a preferência pela região leste; no segundo caso, a preferência pelas camadas populares. As duas entrevistadas disseram se sentir melhor em seu local de moradia. Nesse caso, a utilização da noção de fronteira proposta por José de Souza Martins para interpretar a relação de conflito que ocorre no encontro entre a frente pioneira e a frente de expansão pode ser transportada para dentro da cidade de São Paulo, enxergando a fronteira como uma forma simbólica de luta social.

Porque não estamos falando apenas de "grupos sociais com interesses conflitivos" (MARTins, 1996, p. 27), mas também da existência do "conflito entre historicidades desencontradas". Nesse caso, a própria construção da zona leste já carrega uma carga simbólica negativa no que diz respeito à construção da ideia de sujeira, pobreza, perigo, desordem e disseminação de doenças (CLEMEnTE, 1998). 0 fato de essas pessoas ocuparem a cidade, ou melhor, as casas noturnas de classe média localizadas em regiões mais centrais, gera um motivo de conflito. Talvez esse estranhamento ou afastamento da classe popular referente a essas zonas seja a expressão de uma expulsão subjetiva, por isso a vontade do recuo ou a dificuldade de interpretar os códigos sociais, na ideia de habitus do próprio Bourdieu.

Assim, diferentemente da Plasticine, onde seus frequentadores legitimam baladas e locais com melhor infraestrutura, no Guinga's procura-se o recuo, o afas-

\footnotetext{
${ }^{10}$ Entrevista realizada em setembro de 2012, durante pesquisa de campo.
} 
tamento de casas GLS localizadas nas regiões mais centrais, e a positivação da periferia. Enquanto na Plasticine a periferia aparece como o local da violência e do esteticamente feio, no Guinga's a periferia se dá como o local de segurança e de proximidade entre as pessoas.

\section{A construção do novo no Disturbia}

Em São Mateus, próximo ao Guinga's, encontra-se uma casa chamada Disturbia. Apesar da proximidade espacial, o público dessas duas casas por vezes se choca e por outras interage. Assim, são comuns em conversas informais com o público dessas duas casas as acusações comparativas entre os frequentadores dos dois estabelecimentos. Um dos fatores de distanciamento citado pelo público do Guinga's diz respeito à feminilidade dos gays da outra casa, à desordem, à faixa etária, à presença de travestis e ao som estridente. Em contrapartida, o público do Disturbia aconselhava a não conhecer o Guinga's pelo seu caráter "baixo", "sério", "chato" e de "pessoas velhas". Porém, apesar desse distanciamento, também há um grande número de pessoas que frequentam as duas casas.

Talvez haja uma disputa simbólica pelo significado daquele pedaço, uma busca por legitimação. No caso do Disturbia há uma vontade de construir o homossexual ou mesmo criar estruturas para que esse homossexual se fortaleça, refletido na ideia de gueto, estudado por MacRae (2005) - assim ao resgatar o "bate-cabelo", estilo de música tradicional na cena GLS, a casa ajuda a construir a cultura homossexual. Além do resgate do ser homossexual, também foi identificado nessa casa específica a construção do homossexual de periferia. Nesse sentido, pensar a construção das identidades homossexuais a partir do processo de consumo (FRANÇA, 2006) é válido na medida em que nos possibilita enxergar a produção de diferenças e de sujeitos a partir do mercado.

A criação do novo, ou melhor, de uma casa que fortalece a construção de uma identidade pautada em categorias estigmatizadas - como a feminilidade de gays, a masculinidade de lésbicas, o indivíduo da periferia - foi encontrada nessa boate, em que apresentadores e drag queens da casa realçam uma positividade da periferia, denunciando tanto a visão pejorativa que a periferia sofre, como os olhares discriminatórios de que são alvo as pessoas dessas regiões em ambientes mais elitizados. Assim, a construção de uma identidade homossexual de periferia - termos como "nós somos de São Mateus" versus "eles nos olham como se a gente fosse lixo" - foi 
observada nessa casa específica, fato que nunca presenciamos em nenhuma balada GLS das regiões centrais de São Paulo - muito pelo contrário, as piadas contra a periferia são muito mais intensificadas nesses locais, como no caso de um show em que a apresentadora drag queen respondeu ao frequentador, quando este disse morar em Itaquera: “gente, esconde a bolsa!". A quantidade de piadas desse porte e de risos extremos acabam por contribuir para a degradação das periferias. Nesse sentido, acreditamos que a concepção habermasiana da teoria da ação comunicativa é válida, na medida em que a identificação do marginal, do 'periférico', passa pela produção de um discurso que visa à legitimação de uma classe dominante. Isto também pode ser pensado na própria concepção de Martins no que diz respeito à alteridade, ou seja, a "fronteira do humano", à necessidade de degradar o outro pra viabilizar a existência do dominador.

A faixa etária da casa varia dos 17 aos 24 anos, sendo comum às sextas-feiras maiores de trinta anos, apesar de serem poucos. A casa agrega uma forte presença de pardos a negros, como também um número razoável de travestis. A maior parte dos entrevistados não terminou o Ensino Médio, e muitos deles estão desempregados. Entre as casas noturnas mais citadas estão a Danger, Blue Space e encontros na Avenida Dr. Vieira de Carvalho.

As polaridades de gênero também parecem frequentes. A casa agrega um grande número de gays feminilizados que usam short curto e camisa colada. Grande parte desses jovens homossexuais também faz performances de drag queens. Já entre as meninas, as polaridades são ainda mais discrepantes. No que se refere à roupa, as mulheres masculinizadas vestem sempre tênis, na maior parte de cano longo; blusa amarrada na cintura; calça larga; às vezes boné pra trás, outras sem boné; correntes grandes e pesadas penduradas no pescoço, às vezes cabelo curto com gel, camiseta lisa. Já as mais feminilizadas usam mais top, ou dobram a blusinha de modo a deixar a barriga aparecendo. Roupas coladas ao corpo mostram seu desenho, umbigo a mostra, salto alto. Principalmente entre casais de mulheres, a heteronormatividade estudada por Butler (2003) é mais explícita, estando os binários hierárquicos mais evidentes. Essas performances corporais se expressam também pelas masculinizadas através do uso de blusas amarradas na cintura. Fazendo um paralelo com a análise de Lacombe (2007) sobre o uso do pochete por parte das masculinizadas servindo enquanto simulacro, o mesmo ocorreu no Disturbia, porém ao invés de pochete, o nó da blusa amarrada na parte frontal da cintura cumpre o mesmo papel, 
principalmente no momento do funk. Enquanto a masculinizada fica reta e rígida, parada de braços cruzados, a mais feminilizada rebola o quadril no nó da blusa, peça utilizada como simulacro.

\section{Considerações finais}

A intenção deste paper foi o de registrar o trabalho apresentado no EAIC/ ANPOCS de 2012. Por se tratar de uma pesquisa etnográfica, pretendeu-se mostrar as especificidades das diferentes casas noturnas localizadas nas periferias da zona leste de São Paulo, casas que acabam por contribuir para a construção de diferentes sujeitos. Assim, a presença do gay feminilizado, da lésbica masculinizada, do homossexual 'moderninho', do homossexual 'zona leste', entre outros, só reforça a necessidade de não pensar as diferentes periferias como um todo homogêneo, demonstrando com isso o quanto as casas produzem identidades e o quanto a construção desses atores em campo se entrelaçam e se contradizem, ou seja, como as relações fronteiriças de disputas simbólicas são explícitas até mesmo entre elas.

Olhar a cidade como o local privilegiado para a reflexão de uma forma simbólica de luta social é também pensar o quanto a situação de fronteira colabora para a construção do novo, construção através de disputas que acarretam em novas identidades e novas estratégias de lidar com o conflito. Por fim, ao dar voz ao marginal tanto da perspectiva espacial, como da própria comunidade LGBT - buscou-se tanto o entendimento dos processos que originam esses atores identitários, como o entendimento das homossociabilidades marginais, procurando trabalhar na margem como forma de vencer a própria condição marginal.

\section{Referências}

Bourdieu, P. (1983). "Gostos de classe e estilo de vida". In: Ortiz, R. (Org.). Pierre Bourdieu: sociologia. São Paulo, Ática.

Butler, J. (2003). Problemas de gênero: feminismo e subversão da identidade. Rio de Janeiro, Civilização Brasileira.

Clemente, C. (1998). Apreciando o Movimento: Uma cartografia da periferia da Zona Leste de São Paulo. São Paulo, PUC-SP. Dissertação de Mestrado em Ciências Sociais.

FACCHINI, R. (2008). Entre umas e outras: mulheres, (homo)sexualidades e diferenças na cidade de São Paulo. Campinas, Universidade Estadual de Campinas. Tese de Doutorado em Ciências Sociais. 
FRANÇA, I. (2006). Cercas e pontes: o movimento GLBT e o mercado GLS na cidade de São Paulo. São Paulo, FFLCH-USP. Dissertação de Mestrado em Antropologia Social.

LACombe, A. (2007). "De entendidas e sapatonas: socializações lésbicas e masculinidades em um bar do Rio de Janeiro". Cadernos Pagu, Campinas, n. 28.

Macrae, E. (2005). “Em defesa do gueto”. In: Green, J. N.; Trindade, J. R. (Org.). Homossexualismo em São Paulo e outros escritos. São Paulo, Ed. UNESP.

MAGNANI, J. G. C. (1996). "Quando o campo é a cidade: fazendo antropologia na metrópole". In: MAGNANI, J. G. C.; ToRRES, L. (Org.). Na metrópole: textos de antropologia urbana. São Paulo, Edusp/Fapesp, p. 12-53.

MARTINS, J. (1996). "O tempo da fronteira: retorno à controvérsia sobre o tempo histórico da frente de expansão e da frente pioneira". Tempo social, São Paulo, v. 1, n. 8, p. 25-70.

Recebido em dezembro/2012

Aprovado em fevereiro/2013 